\title{
Fracture behavior and acoustic emission characteristics of sandstone samples with inclined precracks
}

\author{
Litong Dou ${ }^{1,3,4} \cdot$ Ke Yang ${ }^{1,2,3,4} \cdot$ Xiaolou Chi ${ }^{1,3,4}$
}

Received: 23 December 2019/Revised: 2 May 2020/Accepted: 29 June 2020/Published online: 22 July 2020

(C) The Author(s) 2020

\begin{abstract}
Sandstone samples with precracks of different dip angles were collected from a coal mine roof and subjected to uniaxial compression tests, and acoustic emission (AE) and scanning electron microscopy (SEM) were used to study how the crack dip angle affected the fracture mechanism. In the precracked sandstone samples, as the dip angle between the crack line and loading direction decreased, so did the peak stress and its completion time. The SEM observations revealed a fracture transition from tensile cleavage to shear slip, which was manifested by a microstructure change from aggregate to staggered. According to energy conversion, a decreased crack dip angle results in gradually decreasing total and dissipative peak energies, whose variation amplitudes at different stages are consistent with those of the peak stress of the samples. The decreased crack dip angle lowered the stress required to trigger the first appearance of AE energy peaks and ring-down counts, as well as shortening the period before the occurrence of the first AE peak signal. However, the AE energy and ring-down count during the failure stage after the stress peak increased gradually. A stepped increase was observed in the $\mathrm{AE}$ ring-down count curves, with each step corresponding to a jump in the stress-strain curve. From the characteristics of the AE signal of the fracture of a precracked rock sample, the occurrence of joints or faults in the rock mass can be reasonably inferred. This is expected to provide a new method and approach for predicting coal and rock dynamic disasters.
\end{abstract}

Keywords Rock mechanics · Precrack · Fracture mode · Energy conversion · Acoustic emission

Ke Yang

18855485659@163.com

1 State Key Laboratory of Mining Response and Disaster Prevention and Control in Deep Coal Mines, Anhui University of Science and Technology, Huainan 232001, Anhui, China

2 Institute of Energy, Hefei Comprehensive National Science Center, Hefei 230031, Anhui, China

3 National and Local Joint Engineering Research Center of Precision Coal Mining, Anhui University of Science and Technology, Huainan 232001, Anhui, China

4 Key Laboratory of Mining Coal Safety and Efficiently Constructed by Anhui Province and Ministry of Education, Anhui University of Science and Technology, Huainan 232001, Anhui, China

\section{Introduction}

With the ongoing exhaustion of shallow coal resources worldwide, the depth of coal mining is increasing and more hazards are being encountered. The increased frequency and intensity of rock burst disasters in deep mines (Chen et al. 2019; Wang et al. 2019; Ding et al. 2019) can be attributed to deep coal mining; the overlying strata of the coal seam are subjected more to geological factors, including the development of faults and joints therein. Because of earth movement, the dip angle of geological structures also varies during the formation. Therefore, to control and reduce disasters due to instabilities, it is crucial to study the mechanical behavior of rocks with large-scale precracks of different dip angles.

Many studies have addressed the mechanical behavior of coal-rock precracked specimens. Li et al. (2019) studied the fracture modes of coal specimens with cracks of 
different dip angles and used the results of acoustic emission (AE) fractal-dimension measurements at different loading stages as the precursor information of dynamic rock disasters. Mohammadi and Pietruszczak (2019) characterized the failure process of precracked rock specimens and derived the complex fracture mode related to the formation and propagation of new cracks in the region of precracks. Li et al. $(2005,2018)$ conducted dynamic impact tests of rectangular marble precracked specimens; they drilled the rocks, wire-cut them to prepare marble precracked specimens, and then studied their crack propagation behavior. Huang et al. (1990) analyzed the crack propagation trend of a marble specimen with a single crack and proposed five crack propagation routes and the corresponding fracture modes leading to rock failure. Yang et al. $(2011,2016)$ used high-speed photography to evaluate the fracture and instability processes in sandstone specimens containing either a single crack or two parallel noncoplanar cracks, and the results led to evaluation of how the initial crack dip angle and length affected the further crack propagation, coalescence, and residual strength of the cracked sandstone specimens. Lee and Jeon (2011) analyzed crack initiation and propagation in cracked granite samples with either a single or two nonparallel joints and compared the results obtained with those for gypsum samples. Petit and Barquins (1988) tested sandstone specimens with a single crack and different void ratios and found that the shear zone at the crack tip was completely developed after the initiation of a wing crack; moreover, the maximal shear stress direction nearly coincided with the crack line. Bobet (2000) analyzed the propagation mechanism of secondary cracks and proposed a fracture criterion for secondary cracks based on shear stress. Wong and Einstein (2009) performed uniaxial compression tests on precracked gypsum and marble specimens, monitored their evolution via high-speed photography, and classified seven types of secondary cracks emanating from the tips of the original precracks.

Previous studies have analyzed the release pattern of rock elastic waves, and an $\mathrm{AE}$ monitoring system can accurately capture the signals generated during the fracture (Lockner et al. 1991; Cox and Meredith 1993). An AE monitoring system for prefabricated fractured coal-rock materials was made by acquiring and analyzing a series of parameters such as $\mathrm{AE}$ spectrum, $\mathrm{AE}$ energy, and $\mathrm{AE}$ spatiotemporal signals (He et al. 2010; Zhao et al. 2014; Eberhardt et al. 1998; Diederichs et al. 2004; Ganne et al. 2007; Lockner 1993; Moradian et al. 2016; Cao et al. 2019; Li et al. 2017; Pan et al. 2019, Cheng et al. 2019). However, the previous studies were mainly for small-scale cracks of specimens under loading; fewer studies have considered macroscopic defects during rock failure. In fact, the coal-rock materials contain macroscopic structures such as faults, joints, and fractures, significantly affecting the crack propagation and mechanical behavior; this also promotes dynamic disasters in practical engineering. Furthermore, a larger macroscopic structure and its variable occurrence can contribute to dynamic disasters. Meanwhile, these factors also affect significantly the mechanism of $\mathrm{AE}$ signals generated by the fractured coal-rock materials. Therefore, it is essential to study the failure characteristics of prefabricated coal specimens accompanied by macroscopically large scale of sizes and multidip angles. This would also help detect macroscopic geological structures in situ and monitor the failure of joints and coalrock mass. Furthermore, it is very important for predicting dynamic disasters using AE monitoring.

\section{Physico mechanical experiments}

\subsection{Specimen preparation and test scheme}

The sandstone specimens used in this study were collected from the roof of working face 1212(3) in the Panbei Coal Mine of Anhui Province in China. The average depth of the working face is $540 \mathrm{~m}$, and its roof is fine sandstone with a thickness of $20 \mathrm{~m}$. The working face is affected by multiple faults with a drop of more than $4 \mathrm{~m}$. The results of in situ stress tests show that the working face is in a typical tectonic stress field. During the mining process, multiple faulttype ground pressures occurred, which had a great impact on the safety of mining. After sampling, rocks with a large block size were processed using the IRTM (International Rock Test Mechanics) method developed by the International Society for Rock Mechanics (Hudson et al. 1999) to obtain standard specimens as shown in Fig. 1 flowchart of preparation of specimens from large rock samples.

Firstly, a rock core with a diameter of $50 \mathrm{~mm}$ was acquired using a core-drilling machine and was then cut into cylindrical specimens with a height of $105 \mathrm{~mm}$ using a cutting machine. Finally, both end faces of each specimen were ground flat using a grinding machine so that the parallelism error was less than $0.05 \mathrm{~mm}$. The final height of each specimen was $100 \mathrm{~mm}$. Eight standard rock specimens were prepared and subdivided into 4 groups. One group consisted of intact specimens, while the other 3 groups contained specimens with large-scale precracks with dip angles of $30^{\circ}, 45^{\circ}$, and $60^{\circ}$. Precracks in the rock specimens were simulated by slits produced using a diamond disc cutting machine. Each slit was $60 \mathrm{~mm}$ long, $3 \mathrm{~mm}$ wide, and $20 \mathrm{~mm}$ deep, as shown in the bottom part of Fig. 1. The crack dip angle is defined as the angle between the crack line and the axial loading direction. 


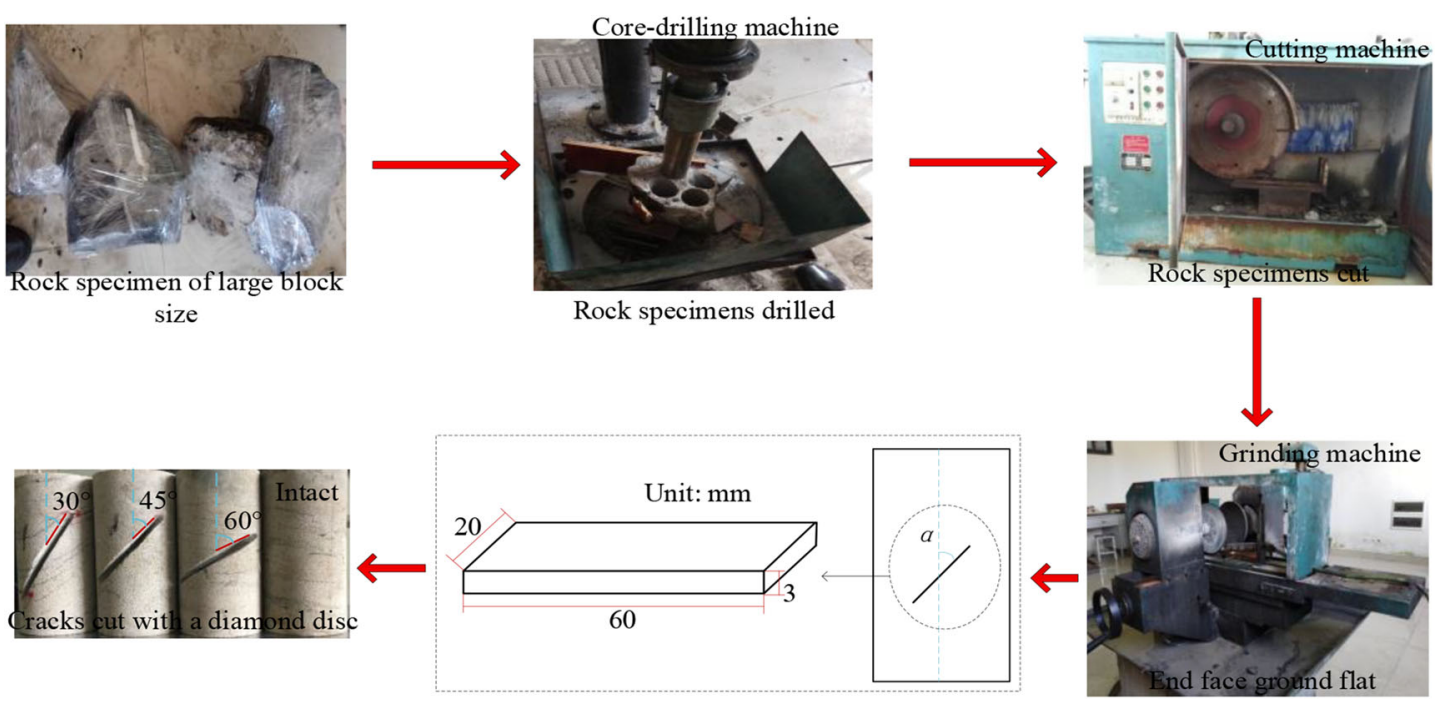

Fig. 1 Flowchart of preparation of specimens from large rock samples

\subsection{Test equipment and monitoring systems}

The testing device comprised systems for loading control, AE monitoring, digital photography, and scanning electron microscopy (SEM), as shown in Fig. 2. During a test, the loading control and AE monitoring systems were started simultaneously to facilitate post-processing of the test results. At the end of the test, the rock fracture morphology was captured using a digital camera, and the fracture surface was scanned using the SEM system.

The loading control system used a multifunction automatic rigid rock servo material testing machine (RMT150B; Institute of Rock and Soil Mechanics; China), which was used to perform conventional uniaxial and triaxial compression tests with high precision. The uniaxial compression tests of sandstone specimens with large-scale precracks were conducted in the load-control mode at a loading rate of $0.5 \mathrm{kN} / \mathrm{s}$.
The AE monitoring system used a multichannel comprehensive information synchronous acquisition device (DS5-16B; Softland Times; China), which could monitor elastic waves in realtime as the specimen was compressed. The AE threshold was set to $40 \mathrm{~dB}$ during the test. The sensor probe was fixed to the specimen with rubber tape, and Vaseline lubricant was used to decrease the friction between them. To ensure good contact between the sensor probe and the specimen, a lead-break test was performed for the $\mathrm{AE}$ sensor before the compression test.

The SEM system used a scanning electron microscope (FlexSEM 1000; Hitachi High-Tech, Japan), achieving a magnification of $60-300 \mathrm{~K}$ and an accelerating voltage of $0.3-20 \mathrm{kV}$.

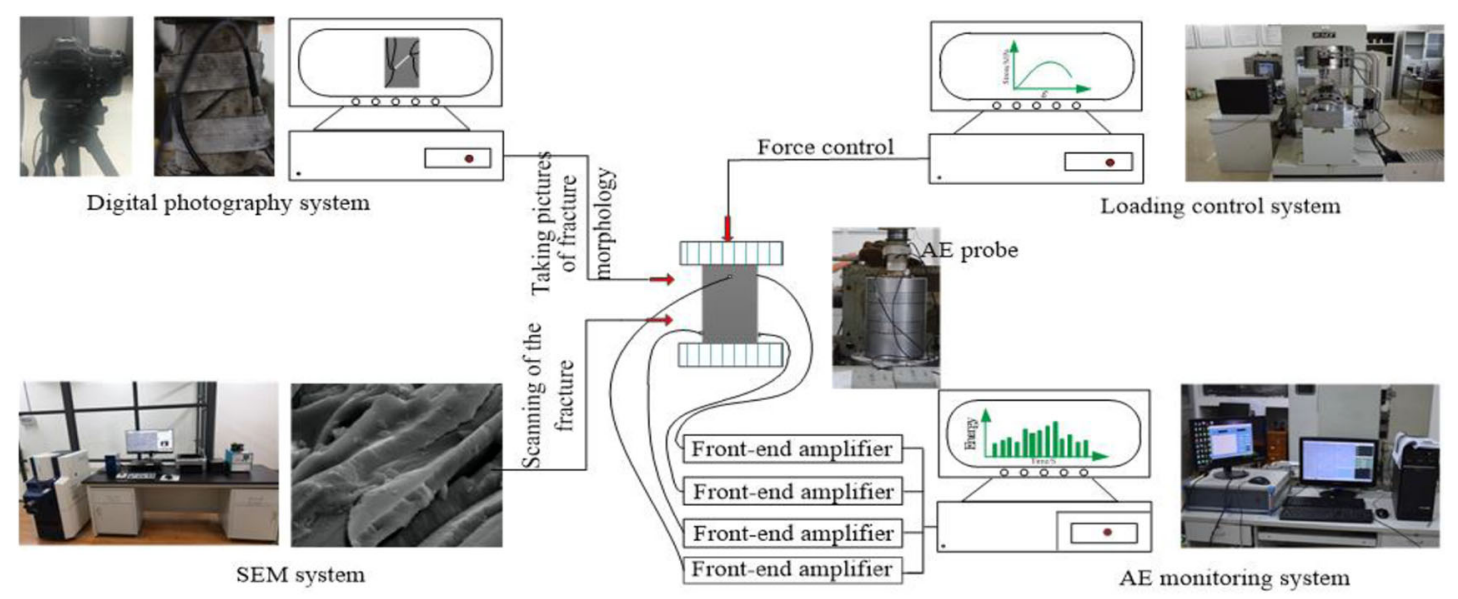

Fig. 2 Loading and monitoring systems 
Fig. 3 Stress-strain curve features and macroscopic fracture morphology of precracked rock specimens with different dip angles: a no cracks; b $60^{\circ} ;$ c $45^{\circ} ;$ d $30^{\circ}$

\section{Mechanical characteristics of precracked rock specimens}

\subsection{Stress-strain curve and fracture morphology}

The stress-strain curve features and macroscopic failure morphology of intact rock specimens and those with precracks are shown in Fig. 3.

Figure $3 \mathrm{a}$ shows the stress-strain curve features and macroscopic fracture morphology of precracked rock specimens with no crack. The specimen compressive strength is $64.45 \mathrm{MPa}$. Upon reaching the peak strength, the stress-strain curve exhibits brittle features, with axial strain of 0.016 . This total stress-strain curve has 4 stages, namely compaction, elastic, plastic, and residual deformation, consistent with the classification made in the study of stress-strain curve features of rocks by Yang et al. (2011). Because the rock specimens of the first group were intact (i.e., contained no precracks), the specimens underwent the stages of compaction of primary cracks, initiation of new cracks, crack propagation and coalescence, and final fracture. As indicated by the fracture morphology of the initially uncracked specimens, they underwent a tensile cleavage fracture (mode I).

Figure $3 \mathrm{~b}$ is as Fig. $3 \mathrm{a}$ but for the rock specimens with a crack dip angle of $60^{\circ}$. Now, under a given load, stress concentration at the precrack tip was more likely to fail, thereby decreasing the compressive strength of these specimens to $49.35 \mathrm{MPa}$ ( $76.6 \%$ of that for the intact specimens). After the peak, the brittle features of the stressstrain curve are enhanced, and the axial strain decreases to 0.014 . According to the ultimate fracture morphology and Tang's (Tang et al. 2001)classification of the propagation mode of secondary cracks, the specimens with a crack dip angle of $60^{\circ}$ featured secondary tensile (mode I) wing cracks emanating from both precrack tips, while a shear (mode II) anti-wing crack propagated toward the specimen top and bottom. These two types of cracks caused the macroscopic failure of the specimen and the loss of its load-bearing capacity. The primary fracture mode of the specimens with a crack dip angle of $60^{\circ}$ was the tensile (mode I) failure starting from the ends of the precrack, and the secondary fracture mode was pure shear (mode II).

Figure $3 \mathrm{c}$ is as Fig. 3a but for the rock specimens with a crack dip angle of $45^{\circ}$. The details are similar to those for a dip angle of $60^{\circ}$. However, because the crack line is closer to the normal to the loading direction, the stress concentration at the precrack tip is higher, decreasing the peak

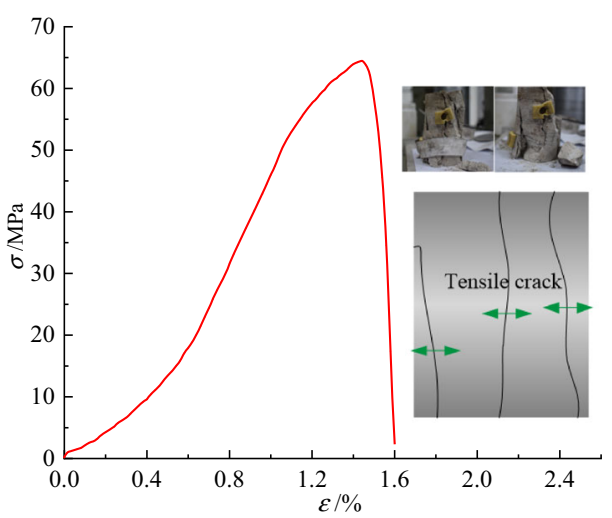

(a)

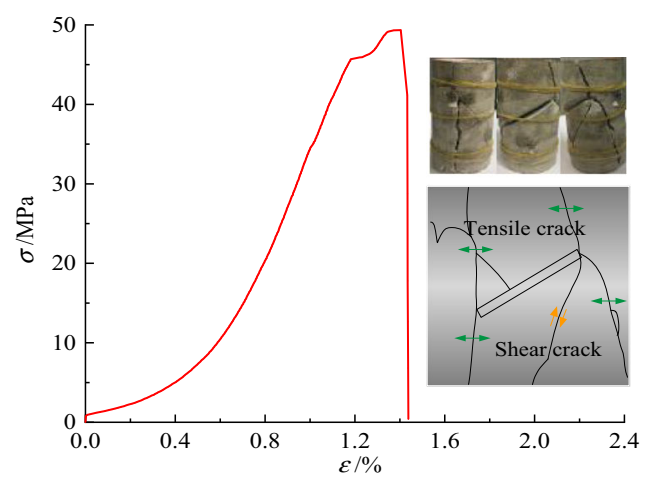

(b)

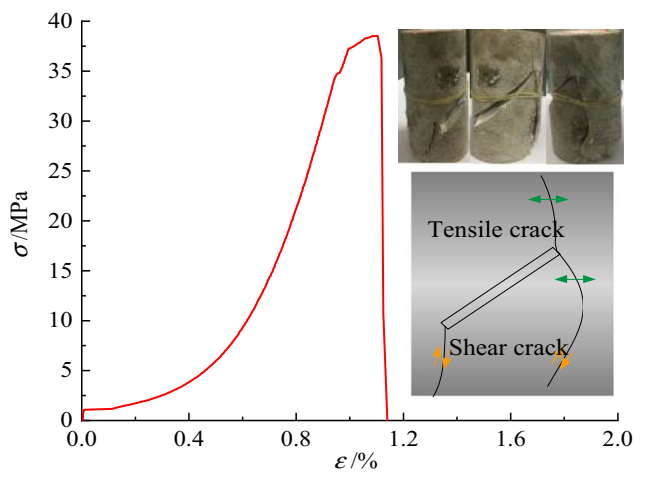

(c)

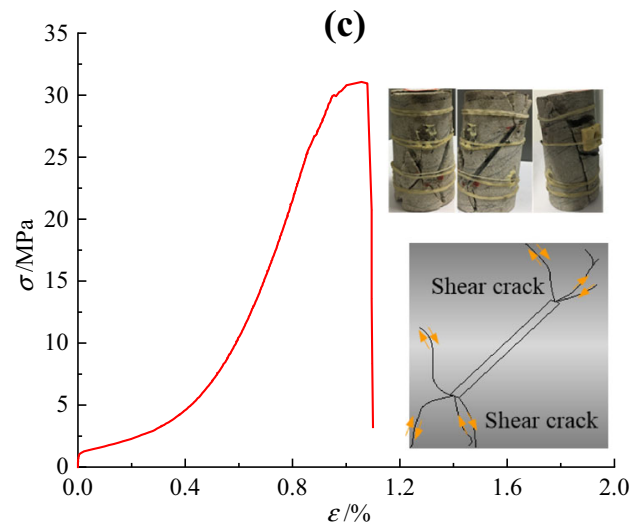

(d) 
strength to $38.53 \mathrm{MPa}(59.8 \%$ of that for the intact specimens). After the peak, the stress-strain curve also exhibits more-conspicuous brittle features, and the axial strain decreases further to 0.0114 . As indicated by the ultimate fracture mode, failure of the specimens with a crack dip angle of $45^{\circ}$ was due mainly to the propagation of a secondary tensile (mode I) wing crack, a tensile-shear (mixed mode I and mode II) composite antiwing crack at the upper end of the precrack, and a shear (mode II) secondary crack at the lower end of the precrack, which propagated to the bottom of the specimen. The fracture mode of the specimens with a crack dip angle of $45^{\circ}$ was typically the mixed (tensile-shear) mode.

Finally, Fig. 3d is as Fig. 3a but for the rock specimens with a crack dip angle of $30^{\circ}$. The trend discussed earlier for the specimens with a dip angle of $45^{\circ}$ is manifested again as follows. The shear stress concentration increased, shear slip fracture was more likely to occur along the precrack, and the compressive strength decreased to $30.94 \mathrm{MPa}$ (48.0\% of that for the intact specimens). After the peak, the stress-strain curve again exhibits more-pronounced brittle features, and the axial strain decreases further to 0.011 . As indicated by their ultimate fracture mode, fracture of the specimens with a crack dip angle of $30^{\circ}$ was due mainly to the propagation of the secondary tensile and shear cracks at both ends of the precrack. The fracture mode was a pure shear mode II of the secondary cracks emanating from both ends of the precrack.

Precrack tips are strong stress raisers, from which secondary cracks initiate and propagate until the ultimate brittle fracture of the specimen. There is a transition from pure tensile (mode I) fracture to mixed (tensile-shear) fracture, which eventually changes to pure shear (mode II). For the stress state at the precrack tip, $\sigma$ is the applied axial stress, $\alpha$ is the dip angle between the precrack and the loading direction, while $\sigma \cos \alpha$ and $\sigma \sin \alpha$ are the stress components parallel and normal, respectively, to the precrack. Changing the crack dip angle from $60^{\circ}$ to $30^{\circ}$ increases $\sigma \cos \alpha$ and decreases $\sigma \sin \alpha$, thereby enhancing the shear slip (mode II) and hampering the tensile cleavage (mode I).

\subsection{Stress and strain evolution patterns}

Figure 4a shows the curves of peak stress and peak strain versus the crack dip angle of the specimens with crack dip angles of $60^{\circ}, 45^{\circ}$, and $30^{\circ}$. As the crack dip angle decreases from $60^{\circ}$ to $45^{\circ}$ and $30^{\circ}$, the peak strength decreases gradually by $23.43 \%, 40.22 \%$, and $51.99 \%$, respectively, compared to that of the intact specimens.

Figure $4 \mathrm{~b}$ shows the transition points between plastic and elastic strain patterns in precracked specimens with various dip angles, closely correlating with the dip angle.

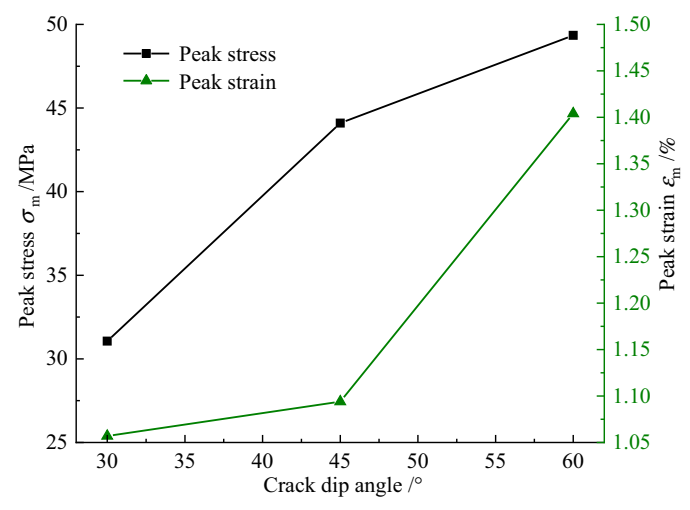

(a)

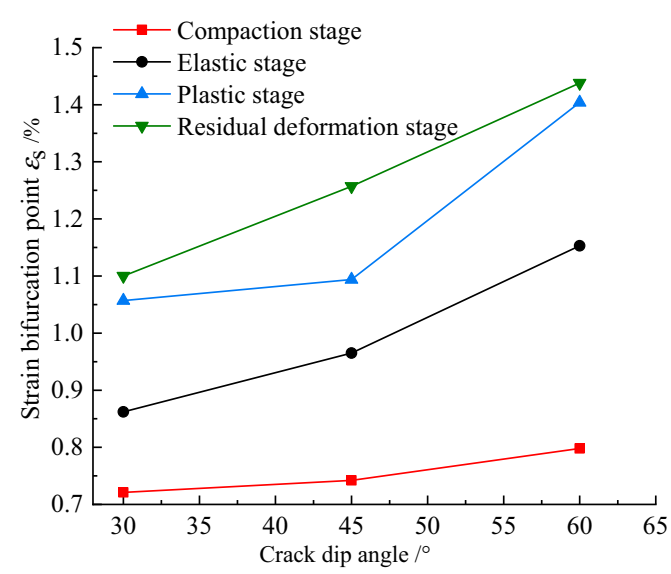

(b)

Fig. 4 Peak stress and strain curves of precracked specimens: a peak strength and strain; $\mathbf{b}$ strain at each dividing point between different stages

The precracked specimens failed mainly in the plastic stage. The presence of a precrack (as the dip angle decreased) caused the fracture mode of the specimen to undergo a transition from tensile fracture to shear fracture. Plastic flow occurred after the shear fracture of the specimen when the dip angle decreased from $45^{\circ}$ to $30^{\circ}$, further increasing its fracture rate. The strain reduction with the dip angle decrease from $60^{\circ}$ to $45^{\circ}$ is larger than that from $45^{\circ}$ to $30^{\circ}$. This variation is consistent with the peak-stress variation pattern.

\subsection{Fracture morphology}

Characterizing the fracture morphology of the specimens with different crack dip angles helps observe the macroscopic effect of dip angle on the specimen fracture pattern. A SEM analysis was performed for the fracture surfaces containing a tensile wing crack with a dip angle of $60^{\circ}$ and a shear wing crack with a dip angle of $30^{\circ}$. The respective SEM images are shown in Fig. 5. 
As shown in the fracture morphology of the tensile crack with a dip angle of $60^{\circ}$ in Fig. 5a, the fracture surface was rough with local undulations, while the overall morphology was basically the same. The randomly distributed convoluted fabrics seen under high magnification are the aggregates formed by the cementing of the crystalline fracture interface after the tensile fracture of the rock crystals, thereby making the fracture surface even rougher.
Figure 5b, c show SEM images of the shear fracture at crack dip angles of $45^{\circ}$ and $30^{\circ}$, respectively. The fracture morphology shows that the fracture surface was relatively smooth. The fracture height varied along a certain direction. As the crack angle decreased, a layered structure of the shear mode was observed. At high magnification, the micro fracture surface was layered: broken lines between
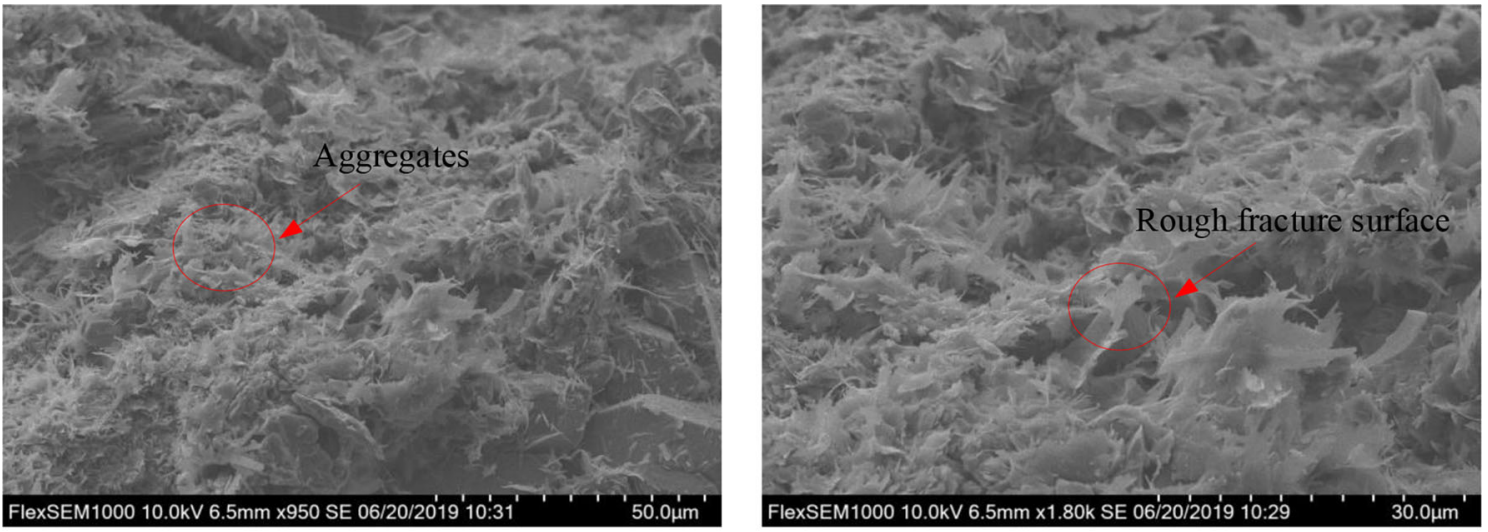

(a)
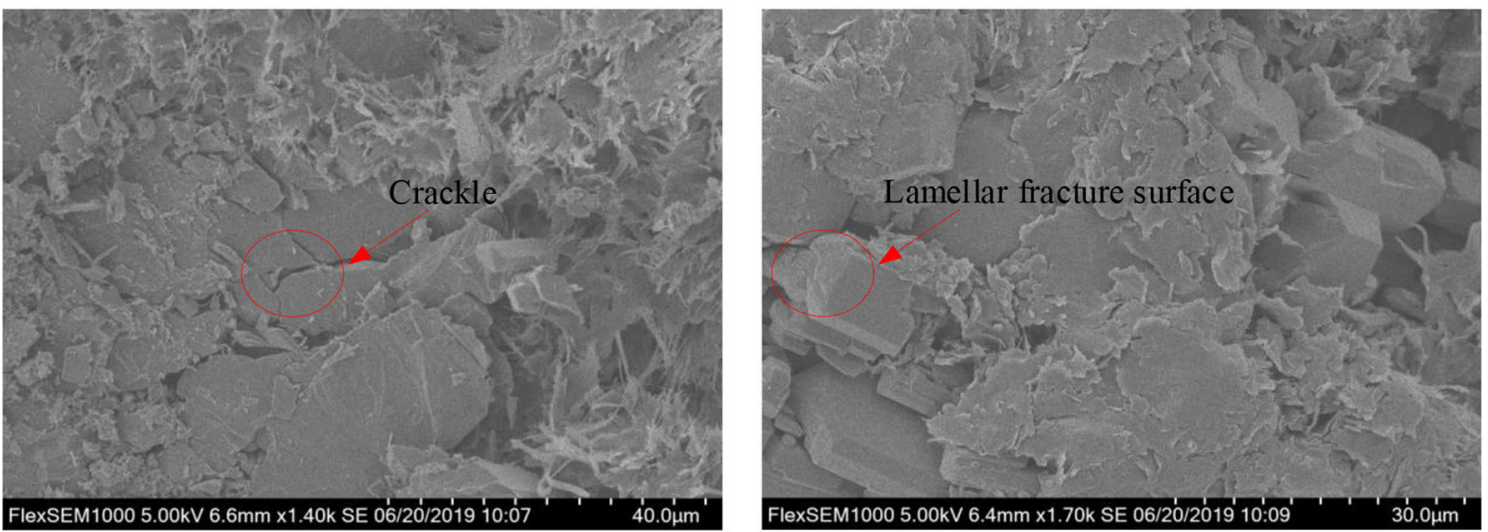

(b)
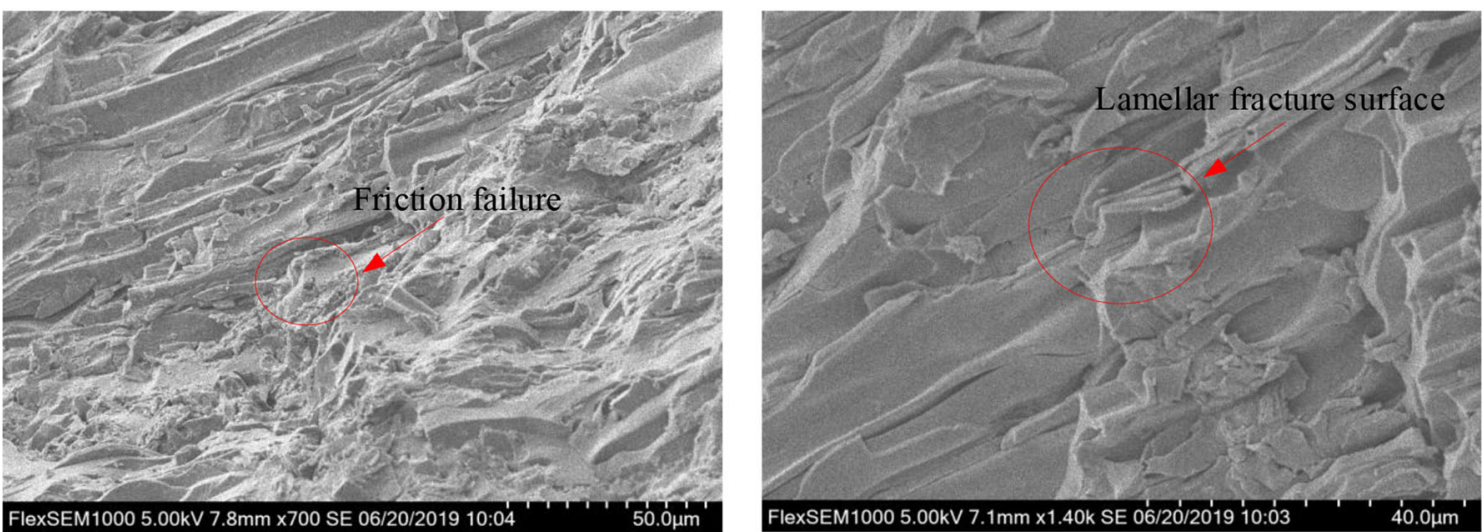

(c)

Fig. 5 SEM images of fractured precracked rock specimens with crack dip angles of a $60^{\circ}, \mathbf{b} 45^{\circ}$, and c $30^{\circ}$ 
the layers had traces of friction, and cracks generally developed at the fracture surface.

The micro fracture morphology was analyzed under the combined tensile and shear action. At low magnification, it was easily observed that the fracture surface was relatively rough under tensile action. At high magnification, aggregates formed at the crystal fracture interface because of tensile stress. By contrast, the shear-induced fracture surface was river-like with a staggered microstructure. As the precrack dip angle decreased, microcracks developed gradually at the fracture surface, and this also caused the specimen strength to decrease with dip angle.

\section{Energy conversion in precracked rock specimens}

\subsection{Theoretical background}

Assuming that energy is converted between the precracked rock specimens and the RMT-150B machine with no heat exchange with an ambient medium, then according to the first law of thermodynamics we have

$U_{\mathrm{o}}=U_{\mathrm{e}}+U_{\mathrm{d}}$,

where $U_{\mathrm{o}}$ is the total energy accumulated in the specimen during the loading; $\mathrm{J} / \mathrm{m}^{3} ; U_{\mathrm{e}}$ is the elastic energy accumulated in the specimen, $\mathrm{J} / \mathrm{m}^{3}$; and $U_{\mathrm{d}}$ is the energy dissipated during fracture, $\mathrm{J} / \mathrm{m}^{3}$.

Figure 6 shows the energy conversion at each stage of a uniaxial compression test of a rock specimen. Based on the differential principle, the averages of $\sigma_{i}$ and $\sigma_{i+1}$ corresponding to the interval $\mathrm{d} \varepsilon$ were taken. According to the interval's lower and upper bounds of zero and $\varepsilon_{1}$, respectively, $U_{\mathrm{o}}$ is derived as

$U_{\mathrm{o}}=\int_{0}^{\varepsilon_{1}} \frac{\sigma_{\mathrm{i}}+\sigma_{\mathrm{i}+1}}{2} \mathrm{~d} \varepsilon$

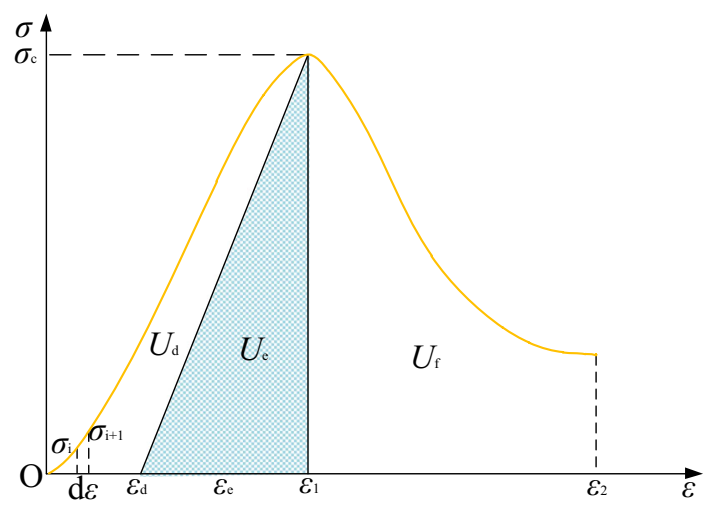

Fig. 6 Energy-conversion process where $\sigma_{i}$ is the stress at any point on the stress-strain curve, $\mathrm{MPa}$ and $\varepsilon_{1}$ is the strain corresponding to the peak stress.

For each loading-unloading cycle of the uniaxial compression test, the unloading route before peak is consistent with the elastic modulus $E$, which is derived as the slope of the stress-strain curve. Therefore, the specimen internal elastic energy $U_{\mathrm{e}}$ can be expressed as

$U_{\mathrm{e}}=\frac{1}{2} \sigma_{\mathrm{c}} \varepsilon_{\mathrm{e}}$,

where $\sigma_{\mathrm{c}}$ is the peak strength of the specimen and $\varepsilon_{\mathrm{e}}$ is the recoverable strain.

The total stored energy before the peak consists of $U_{\mathrm{e}}$ and $U_{\mathrm{d}}$ energies. The latter can be expressed as

$U_{\mathrm{d}}=U_{\mathrm{o}}-U_{\mathrm{e}}=\int_{0}^{\varepsilon_{1}} \frac{\sigma_{\mathrm{i}}+\sigma_{\mathrm{i}+1}}{2} \mathrm{~d} \varepsilon-\frac{1}{2} \sigma_{\mathrm{c}} \varepsilon_{\mathrm{e}}$.

The released energy $U_{\mathrm{f}}$ after the peak is the envelope area from $\varepsilon_{1}$ and $\varepsilon_{2}$, expressed as

$U_{\mathrm{f}}=\int_{\varepsilon_{1}}^{\varepsilon_{2}} \frac{\sigma_{\mathrm{i}}+\sigma_{\mathrm{i}+1}}{2} \mathrm{~d} \varepsilon$,

where $\varepsilon_{2}$ is the maximum strain of the stress-strain curve.

Some of the elastic energy $U_{\mathrm{e}}$ before the peak is converted into released energy $U_{\mathrm{f}}$ after the peak, and the rest is converted into surplus energy $U_{\mathrm{y}}$. The latter part can be further converted into kinetic energy, thus inducing dynamic disasters. The surplus energy $U_{\mathrm{y}}$ can be expressed as

$U_{\mathrm{y}}=U_{\mathrm{e}}-U_{\mathrm{f}}=\frac{1}{2} \sigma_{\mathrm{c}} \varepsilon_{\mathrm{e}}-\int_{\varepsilon_{1}}^{\varepsilon_{2}} \frac{\sigma_{\mathrm{i}}+\sigma_{\mathrm{i}+1}}{2} \mathrm{~d} \varepsilon$.

\subsection{Effect of precracks on energy conversion}

Based on the above theoretical background, Fig. 7 shows the energy-conversion curves of rock specimens with a precrack.

Figure 7a shows the total accumulated and dissipative energy curves for specimens with a precrack before the peak. As the crack dip angle decreases, both the total and dissipative energy peaks decrease gradually. The total peak energies of the specimens with a precrack (as the dip angle decreases) decrease by $26.7 \%$ and $39.1 \%$, respectively, while the dissipative peaks decrease by $19.7 \%$ and $31.9 \%$, respectively. This is consistent with the peak-stress variation trend. This is mainly because increasing the crack dip angle also enhances the structural effect. However, largescale precracks impair the integrity of the rock specimens and change the distribution of horizontal additional stresses in specimens containing defects (i.e., a large-scale precrack) during the loading (Pan et al. 2013; Yin et al. 2018). This further increases the stress concentration at the precrack tip and decreases the load-bearing capacity of the 


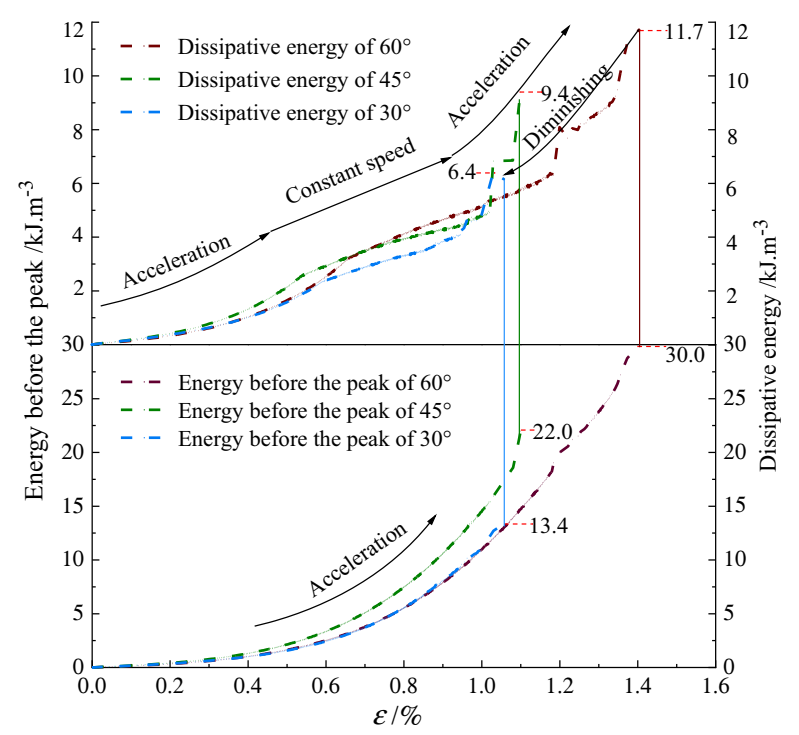

(a)

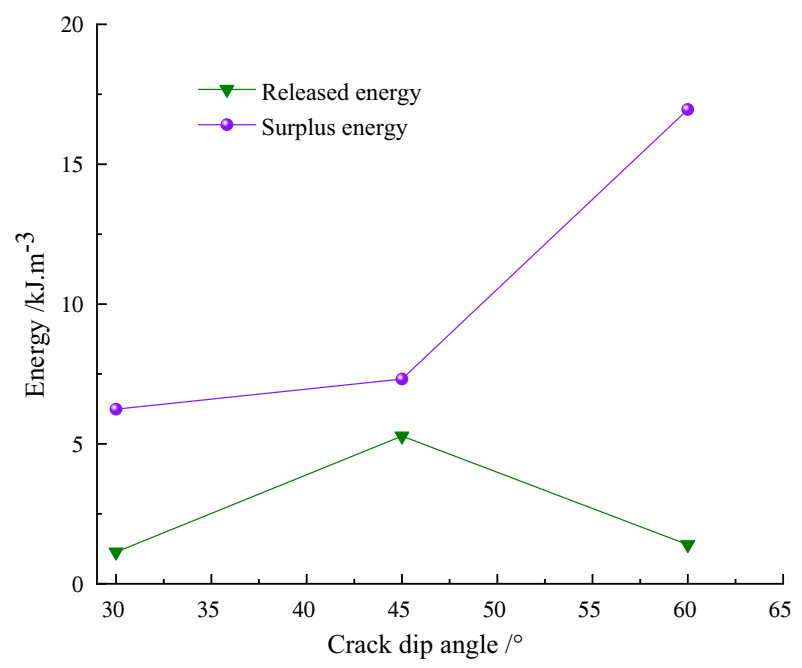

(b)

Fig. 7 Energy-conversion rules for precracked rock samples: a before peak; $\mathbf{b}$ after peak

specimen. Consequently, the total accumulated energy varies. According to the total and dissipative energy curves, the highest increase rate is that for a crack dip angle of $45^{\circ}$, which undergoes a mixed tensile-shear failure. The initiation and propagation rates of mixed-mode secondary cracks emanating from the precrack are much higher than those obtained under pure tensile or shear fracture modes.

Figure $7 \mathrm{~b}$ shows the released and surplus energy curves of precracked specimens after the peak. The presence of precracks caused the specimens to exhibit brittle failure features, resulting in a smaller peak released energy after the peak. The failure process of the rock specimens with large-scale precracks involved the initiation and propagation of cracks emanating from the precrack tips. Macroscopic tensile-shear cracks appeared at the specimen surface, and later the elastic energy stored in the specimen was released rapidly through the macroscopic tensile-shear cracks. This part of the energy would cause massive delamination of rock layers near the precracks and structural changes of defect-containing specimens.

\section{AE testing of precracked rock specimens}

\subsection{AE energy and ring-down count}

Figure 8a-c combine the stress-time curves and AE energy and $\mathrm{AE}$ ring-down count curves constructed during the fracture process under uniaxial compression tests of precracked rock specimens with different dip angles. The AE ring-down count is the number of times that an $\mathrm{AE}$ transient crosses the detection threshold and causes the sensor to ring like a bell. At the compaction stage of the rock specimens, the loading stress was small, and the primary cracks underwent deformation and closure, whereas the secondary cracks were initiated and developed. The area of microcracks was small, and the friction, dislocation, and tensile-shear fracture between the cracks were low-scale. At this stage, few elastic waves were generated, and crack compaction, initiation, and propagation had only a microscopic scale, and the AE energy and ring-down count were still low. As the load increased, the energy output of the test machine was transferred to the rock specimen in the form of elastic energy. This process was accompanied by the compaction and propagation of primary cracks, as well as the initiation and propagation of secondary cracks. Under different dip angles of precracks, the first peaks of $\mathrm{AE}$ energy and $\mathrm{AE}$ ring-down count occurred at different positions. However, all of them fell within the elastic stage of the stress-time curve for crack dip angles of $60^{\circ}, 45^{\circ}$, and $30^{\circ}$. Specifically, the time nodes were 101,75 , and $37 \mathrm{~s}$, respectively. The AE ring-down counts were 654, 2687, and 5469, respectively, and macroscopic cracks appeared at the specimen surface for the first time. At this stage, the elastic energy stored in the rock specimen was released via its weak surfaces, such as macroscopic cracks. Cracking sounds could be heard, and the AE energy and AE ring-down count increased suddenly, similar to a single earthquake wave. As the precrack dip angle decreased, the first peaks of AE energy and AE ring-down count occurred, and the corresponding loading stresses were 25.6, 18.9, and $9.2 \mathrm{MPa}$, respectively. Thus, as the precrack dip angle decreased, the loading stress needed for the first appearance of macroscopic cracks at the specimen surface (first peaks of $\mathrm{AE}$ energy and $\mathrm{AE}$ ring-down count) decreased. The macroscopic cracks occurred earlier for the following possible reasons. As the precrack dip angle decreased, there was a transition from tensile cleavage failure to pure 


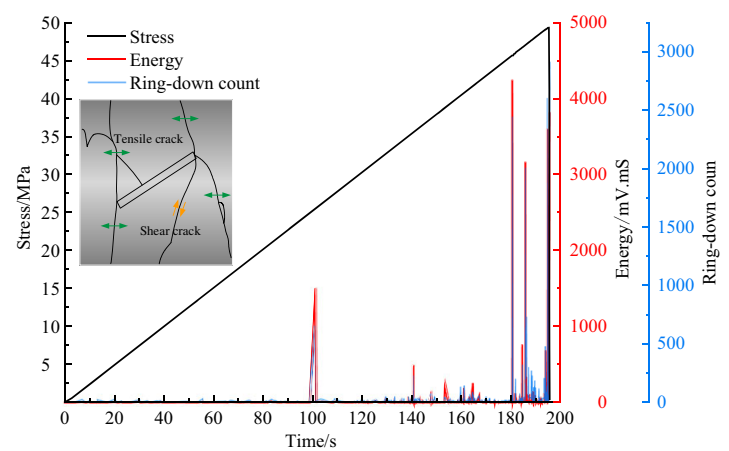

(a)

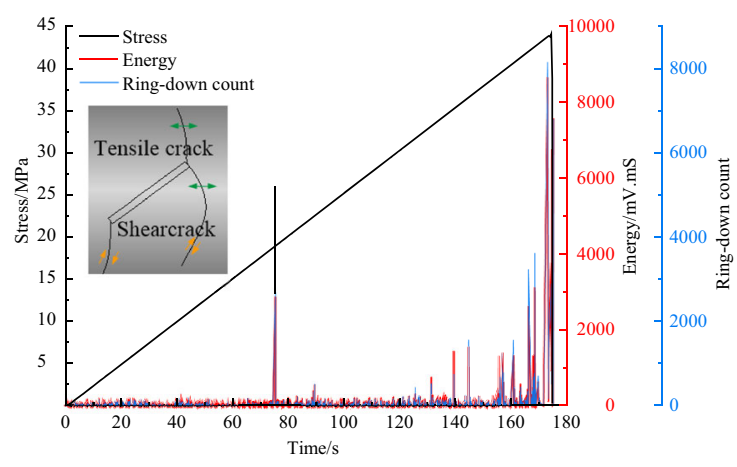

(b)

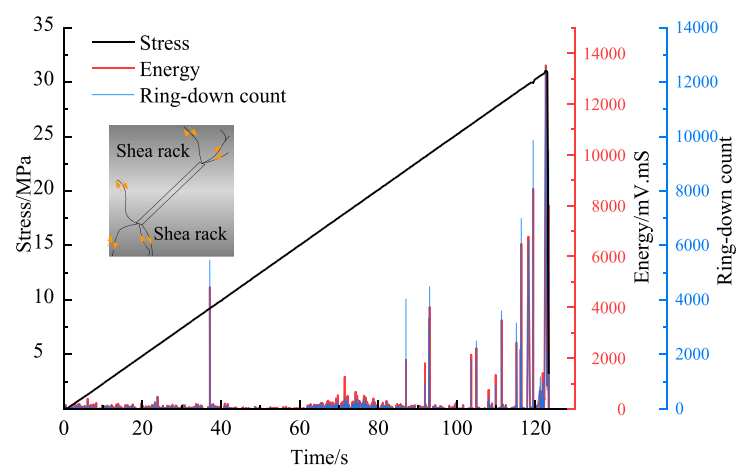

(c)

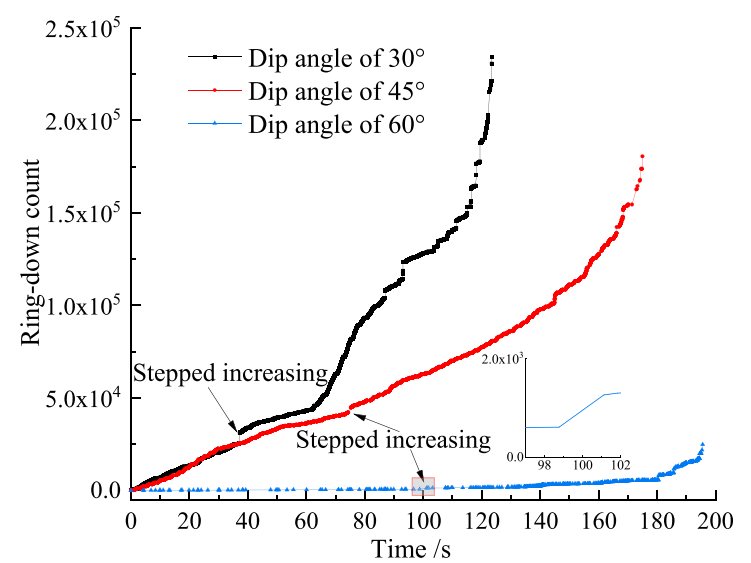

(d)
४Fig. 8 Acoustic emission (AE) features of precracked rock specimens: a crack dip angle of $60^{\circ} ; \mathbf{b}$ crack dip angle of $45^{\circ}$; $\mathbf{c}$ crack dip angle of $30^{\circ} ; \mathbf{d}$ cumulative $\mathrm{AE}$ ring-down count

shear. This transition enhanced the frictional effect between fracture surfaces, and the elastic wave released increases. Even under smaller external loads, large elastic waves were released within the rock specimen, and on the macroscopic scale, the peak $\mathrm{AE}$ energy and $\mathrm{AE}$ ring-down count occurred earlier.

The stress-time curve of the precracked rock specimens entered the plastic and residual deformation stages, and multiple peaks of $\mathrm{AE}$ energy and $\mathrm{AE}$ ring-down count were observed, similar to repeated earthquake shocks. Such sudden jumps correspond to where the stress-time curved rops sharply and occurred mainly in the plastic stage (where the stress increased with the fluctuation before the peak) and the elastic deformation stage (where the brittleness decreased linearly after the peak). At these two stages, multiple new cracks propagated and coalesced at the precrack tip, thereby increasing the density of elastic waves within the specimen. Moreover, as the precrack dip angle decreased, both the $\mathrm{AE}$ energy and $\mathrm{AE}$ ring-down count increased at these two stages. This is because as the precrack dip angle decreased, a transition occurred from the mixed (tensile-shear) mode to the pure shear mode. Based on the fracture morphology of the tensile and shear modes obtained via SEM, the frictional effect between cracks in the specimen was enhanced, and more macroscopic cracks appeared and coalesced. The elastic energy accumulated before the peak was released rapidly via weak surfaces such as cracks, resulting in the delamination and peeling-off of crack faces. During this process, numerous elastic waves were released, and the AE energy and ringdown count increased. The smaller the precrack dip angle, the more pronounced the phenomenon.

\subsection{Cumulative ring-down count}

Figure $8 \mathrm{~d}$ combines the cumulative $\mathrm{AE}$ ring-down count curves of the precracked rock specimens with different dip angles. A stepped increasing trend is observed in these curves, where each step represents a jump in the stressstrain curve. The cumulative $\mathrm{AE}$ ring-down curve of the rock specimens with a crack dip angle of $30^{\circ}$ first appeared the step point, followed by those with angles of $45^{\circ}$ and $60^{\circ}$. Also, the rise of the first step point is higher than those for $45^{\circ}$ and $60^{\circ}$. The number of step points that occurred during the cumulative $\mathrm{AE}$ ring-down of the rock specimens with a crack dip angle of $30^{\circ}$ was more than those for $45^{\circ}$ and $60^{\circ}$. The step points in the cumulative $\mathrm{AE}$ ring-down curve for the specimens with a crack dip angle of $60^{\circ}$ were 
concentrated mainly in the post-peak failure phase, those for the specimens with a crack dip angle of $45^{\circ}$ were concentrated mainly in the plastic phase and post-peak failure phase, and those for the specimens with a crack dip angle of $30^{\circ}$ were distributed throughout the rock failure stage. The cumulative AE ring-down count of the rock specimens was the highest fora crack dip angle of $30^{\circ}$, followed in turn by those with angles of $45^{\circ}$ and $60^{\circ}$. The corresponding cumulative loading duration was the smallest under a crack dip angle of $30^{\circ}$, followed in turn by $45^{\circ}$ and $60^{\circ}$. The steepest step was observed for a dip angle of $30^{\circ}$, and the smallest one was observed at $60^{\circ}$. Thus, the number of cracks was the highest and their propagation was the fastest for a dip angle of $30^{\circ}$. The energy release was also the most pronounced. More cracks were observed in the case of a dip angle of $60^{\circ}$ than $45^{\circ}$, even though the crack propagation speed was the lowest. This is because the normal to the precrack direction at $60^{\circ}$ was closer to the loading direction, and the deformation and closure of primary cracks during the loading process were much larger than those for $45^{\circ}$. Therefore, primary damages such as microcracks within the specimen had more time to evolve, the crack propagation slowed down, and the released energy was weaker. The compressive strength of the precracked specimens with a dip angle of $45^{\circ}$ was higher than that for $60^{\circ}$, and at this time the structural effect was enhanced.

\section{Conclusions}

The presence of precracks deteriorated the compressive strength and deformation features of coal-rock specimens. As the precrack dip angle decreased, the compressive strength of the sandstone specimens decreased gradually, and the time to peak stress was also shortened. The axial strain upon failure decreased, and a transition from cleavage to shear mode occurred.

(1) The fracture surface was rough. Crystal aggregates appeared at the fracture interface. Under shear mode, the fracture surface had a layered structure, with traces of friction and developed microcracks.

(2) As the dip angle decreased, the first peaks of $\mathrm{AE}$ energy and ring-down count occurred earlier. A stepped increasing trend was observed in the cumulative ring-down count curves at the rock failure stage.

(3) Based on the first high-value $\mathrm{AE}$ signals and the turning point of cumulative AE ringing amounts, the macroscopic geological structure can be detected onsite, and the occurrence of coal-rock mass faults can also be reasonably inferred. This method provides a new method for predicting coal-rock dynamic disasters.

Acknowledgements The authors are grateful for the support received from the National Natural Science Foundation of China (Grant No. 51634007) and the Graduate Innovation Fund project of Anhui University of Science and Technology (Grant No. 2019CX1003).

\section{Compliance with ethical standards}

Conflict of interest The authors declare that they have no known competing financial interests or personal relationships that could have appeared to influence the work reported in this paper.

Open Access This article is licensed under a Creative Commons Attribution 4.0 International License, which permits use, sharing, adaptation, distribution and reproduction in any medium or format, as long as you give appropriate credit to the original author(s) and the source, provide a link to the Creative Commons licence, and indicate if changes were made. The images or other third party material in this article are included in the article's Creative Commons licence, unless indicated otherwise in a credit line to the material. If material is not included in the article's Creative Commons licence and your intended use is not permitted by statutory regulation or exceeds the permitted use, you will need to obtain permission directly from the copyright holder. To view a copy of this licence, visit http://creativecommons. org/licenses/by/4.0/.

\section{References}

Bobet A (2000) The initiation of secondary cracks in compression. Eng Fract Mech 66(2):187-219

Cao AY, Jing GC, Ding YL, Liu S (2019) Mining-induced static and dynamic loading rate effect on rock damage and acoustic emission characteristic under uniaxial compression. Saf Sci 116:86-96

Cheng XY (2019) Damage and failure characteristics of rock similar materials with pre-existing cracks. Int J Coal Sci Technol 6(4):505-517

ChenXJ LiLY, WangL QiLL (2019) The current situation and prevention and control countermeasures for typical dynamic disasters in kilometer-deep mines in China. Saf Sci 115:229-236

Cox SJD, Meredith PG (1993) Microcrack formation and material softening in rock measured by monitoring acoustic emissions. Int J Rock Mech Min Sci Geomech Abstr Pergam 30(1):11-24

Diederichs MS, Kaiser PK, Eberhardt E (2004) Damage initiation and propagation in hard rock during tunnelling and the influence of near-face stress rotation. Int $J$ Rock Mech Min Sci 41(5):785-812

Ding X, Xiao XC, Wu D, Lv XF (2019) Mechanical properties and charge signal characteristics in coal material failure under different loading paths. Int J Coal Sci Technol 6(1):138-149

Eberhardt E, Stead D, Stimpson B, Read RS (1998) Identifying crack initiation and propagation thresholds in brittle rock. Can Geotech J 35(2):222-233

Ganne P, Vervoort A, Wevers M (2007) Quantification of pre-peak brittle damage: correlation between acoustic emission and observed micro-fracturing. Int $\mathrm{J}$ Rock Mech Min Sci 44(5):720-729

He MC, Miao JL, Feng JL (2010) Rock burst process of limestone and its acoustic emission characteristics under true-triaxial unloading conditions. Int J Rock Mech Min Sci 47(2):286-298 
Huang JF, Chen GL, Zhao YH, Wang R (1990) An experimental study of the strain field development prior to failure of a marble plate under compression. Tectonophysics 175(1-3):269-284

Hudson JA, Crouch SL, Fairhurst CE (1999) Soft, stiff and servocontrolled testing machines. Int $J$ Rock Mech Min Sci 36(3):279-289

Lee H, Jeon S (2011) An experimental and numerical study of fracture coalescence in pre-cracked specimens under uniaxial compression. Int J Solids Struct 48(6):979-999

Li HG, Li HM (2017) Mechanical properties and acoustic emission characteristics of thick hard roof sandstone in Shendong coal field. Int J Coal Sci Technol 4(2):147-158

Li YP, Chen LZ, Wang YH (2005) Experimental research on precracked marble under compression. Int $\mathrm{J}$ Solids Struct 42(9):2505-2516

Li DY, Han ZY, Sun XL, Zhou T, Li XB (2018) Dynamic mechanical properties and fracturing behavior of marble specimens containing single and double flaws in SHPB tests. Rock Mech Rock Eng 52:1-21

Li DX, Wang EY, Kong XG, Ali M, Wang DM (2019) Mechanical behaviors and acoustic emission fractal characteristics of coal specimens with a pre-existing flaw of various inclinations under uniaxial compression. Int J Rock Mech Min Sci 116:38-51

Lockner D (1993) The role of acoustic emission in the study of rock fracture. Int $J$ Rock Mech Min Sci Geomech Abstr 30(7):883-899

Lockner DA, Byerlee JD, Kuksenko V, Ponomarev A, Sidorin A (1991) Quasi-static fault growth and shear fracture energy in granite. Nature 350(7):39-42

Mohammadi H, Pietruszczak S (2019) Description of damage process in fractured rocks. Int J Rock Mech Min Sci 113:295-302

Moradian Z, Einstein HH, Ballivy G (2016) Detection of cracking levels in brittle rocks by parametric analysis of the acoustic emission signals. Rock Mech Rock Eng 49(3):785-800
Pan YS, Tang Z, Li ZH, Zhu LY, Li GZ (2013) Research on the charge inducing regularity of coal rock at different loading rate in uniaxial compression tests. Chin J Geophys 56(3):1043-1048

Pan WD, Wang X, Liu QM, Yuan YK, Zuo BD (2019) Non-parallel double-crack propagation in rock-like materials under uniaxial compression. Int J Coal Sci Technol 6(3):372-387

Petit JP, Barquins M (1988) Can natural faults propagate under mode II conditions. Tectonics 7(6):1243-1256

Tang CA, Lin P, Wong RHC, Chau KT (2001) Analysis of crack coalescence in rock-like materials containing three flaws-part II: numerical approach. Int J Rock Mech Min Sci 38(7):925-939

Wang HW, Shi RM, Lu CS, Jiang YD, Deng DX, Zhang DQ (2019) Investigation of sudden faults instability induced by coal mining. Saf Sci 115:256-264

Wong LNY, Einstein HH (2009) Systematic evaluation of cracking behavior in specimens containing single flaws under uniaxial compression. Int J Rock Mech Min Sci 46(2):239-249

Yang SQ (2011) Crack coalescence behavior of brittle sandstone samples containing two coplanar fissures in the process of deformation failure. Eng Fract Mech 78(17):3059-3081

Yang SQ, Jing HW (2011) Strength failure and crack coalescence behavior of brittle sandstone samples containing a single fissure under uniaxial compression. Int J Fract 168(2):227-250

Yang SQ, Tian WL, Huang YH, Ranjith PG, Ju Y (2016) An Experimental and numerical study on cracking behavior of brittle sandstone containing two non-coplanar fissures under uniaxial compression. Rock Mech Rock Eng 49(4):497-1515

Yin DW, Chen SJ, Xing WB, Huang DM, Liu XQ (2018) Experimental study on mechanical behavior of roof-coal pillar structure body under different loading rates. J China Coal Soc 43(5):1249-1257

Zhao XG, Wang J, Cai M, Cheng C, Ma LK, Su R, Zhao F, Li DJ (2014) Influence of unloading rate on the strainburst characteristics of Beishan granite under true-triaxial unloading conditions. Rock Mech Rock Eng 47(2):467-483 